\title{
FINDINGS OF A MEE'TING OF LEPROSY WORKERS
}

Convenid at the Office of the British Empire Leprosy Rililif Association, 167, Victoria Street, London, S.W.1., on Monday, September 17Th, 1951, At 10.30 A.M.

\section{AGENDA}

I. To review the present position with reference to chemotherapy in leprosy, and issue an agreed statement for the guidance of workers in the field.

2. To review the present position with regard to the use of B.C.G. in the leprosy campaign.

Present: Dr. E. Muir, Medical Adviser, B.E.L.R.A. (Chairman), Dr. R. G. Cochrane, Medical Secretary, B.E.L.R.A., Dr. John Lowe, Medical research worker to the Government of Nigeria, Dr. T. F. Davey, Area Superintendent, Nigeria Leprosy Service, Uzuakoli, Nigeria, Dr. and Mrs. Barnes, Ogoja Leprosy Settlement, Nigeria, Dr. J. Ross Innes, Inter-territorial Leprologist, E. African High Commission, Dr. J. A. K. Brown, recently appointed Adviser on Leprosy to the Government of Uganda.

\section{SULPHONE TREATMENT OF LEPROSY}

\section{Giniral.}

(I) The development of sulphone therapy has now reached the stage when it can be strongly recommended as the basic routine treatment of all active cases of leprosy. Some of us consider that Hydnocarpus Oil treatment by intradermal injections is a useful supplementary treatment.

(2) The mode of action of sulphones is not completely understood. It is probable that the more complex (disubstituted) sulphones are rendered active by being broken down to simple compounds (DDS and probably mono-substituted and other sulphones). The therapeutic action of sulphones can be obtained by administering any of these.

(3) The giving of disubstituted sulphones in the usually recommended doses by mouth is an effective, but uneconomic, method of treatment, and need not be further considered here.

(4) Our experience of disubstituted sulphones by injections is practically confined to sulphetrone. Such injections are considered to provide a cheap and effective form of treatment.

(5) Monosubstituted sulphones are reported to be active per se, and when given orally, to provide a safe and effective 
treatment of leprosy. Our experience of them is very limited. Their cost at present excludes their use on a large scale.

(6) DDS (parent sulphone, diaminodiphenylsulphone) is highly active and is so well absorbed and so slowly excreted, that its effective dose is very low. Its oral administration is simple and effective, but its insolubility renders injections troublesome.

\section{COMPlications OF TREATMENT, TOXIC AND OTHERWISE.}

The complications of treatment here mentioned have bcen seen in all forms of sulphone therapy. They are much less common and less severe with the drugs and doses now recommended than in the past, but they still may occur. Sulphone treatment needs workers capable of detecting and dealing with these complications as they arise.

(a) Reaction, neuritis, etc., though seen in cases without treatment, is more common in cases under sulphone therapy, particularly in the early phases. If it is mild, the treatment has to be stopped until it has subsided. Injections of antimony are com. monly used in the treatment of this complication, but results are not constant, and some favour other remedies. In time the condition subsides, but frequently recurs. For severe neuritis, procaine injections into the affected nerve have been found useful.

(b) Drug fever, with general dermatitis, hepatitis, lymphadenitis, etc. This complication has been recorded as frequent in West Africa, where it seems probable that a local factor contributes to its causation. The fever in lymphadenitis and hepatitis is indistinguishable clinically and serologically from glandular fever (infectious mononucleosis). The dermatitis, which may be severe and exfoliate, is similar to other severe drug dermatitis (arsenical and sulphonamide). The whole condition is caused by an intense allergy to sulphones and sulphonamides.

Early diagnosis, immediate cessation of sulphones, the avoidance of sulphonamides, and anti-histamine treatment are of great importance. A failure in this matter may lead to death.

When the condition has subsided, sulphone treatment can be resumed only after very careful desensitization, starting at minute doses. In desensitization oral administration twice weekly of a soluble sulphone (e.g. sulphetrone) rising slowly from $5 \mathrm{mgm}$. is very useful.

The syndrome makes its first appearance always during the first few weeks of treatment, though it may recur later. The first three months of treatment need careful watching. The very 
gradual induction of treatment is advisable to minimise the danger.

(c) Anaemia. In well nourished patients treated with the doses recommended below, serious anaemia is rare. When it occurs, factors other than sulphone treatment usually contribute (e.g. malnutrition, hook worm, etc.). In severe lepromatous cases, leprosy itself frequently causes aneamia. Routine haemoglobin estimations are unnecessary. Proper clinical examination will detect any cases of anaemia. Iron administration is not necessitated by sulphone treatment, as here outlined, though in ill-nourished patients with parasitic infections it is advisable.

(d) Hepatitis is usually a part of the drug fever syndrome described above. It has however been seen separately. Treatment must be stopped until the patient has fully recovered.

(e) Cyanosis. This is rarely visible in dark skinned people, but in others it is not uncommon. It is reliably reported to be more common in patients living at high altitudes (above 5,000 ft.), when it may cause serious distress. Apart from this, it is usually of little or no significance.

(f) Psychosis. On the higher doses previously used (particularly with DDS) this complication was not uncommon. Now on the lower doses it is rare. It commonly occurs only after prolonged continuous treatment. It is characterised by excitement, by depression, or by alternating phases of excitement and depression. There may be a tendency to suicide. The psychosis slowly subsides when sulphones are withdrawn. Sulphone treatment can later be resumed at a lower dosage, or an alternative treatment, such as thiosemicarbazone, may be substituted.

\section{Recommended Forms of Treatment.}

The two forms of treatment which are simple, cheap and widely applicable are here outlined. Other forms of treatment, though probably not less effective, are much more costly and less widely practicable.

(a) Sulphetrone (pure crystals). 50\% solution in distilled water sterilised in an autoclave at 15 lbs. for 30 mins. or boiled for 30 mins.

Intramuscular or subcutaneous injections are given:-

First two weeks $\quad \ldots \quad \ldots \quad .5$ c.c. (0.25 g.) twice a week

Second two weeks $\ldots \quad \ldots \quad$ I.0 c.c. $(0.5$ g.) ," ,"

Third two weeks ... ... I.5 c.c. $(0.75$ g.) ," ,

Fourth two weeks ... $\quad$... 2.0 c.c. (I.0 g.) ", ",

Fifth two weeks $\ldots \quad \ldots \quad 2.5$ c.c. (I.25 g.) , ,

Thereafter $\ldots \quad \ldots \quad \ldots \quad$ 3.0 c.c. (I.5 g.) , , 
(b) DDS. Supplied in $100 \mathrm{mg}$. and $50 \mathrm{mg}$. tablets. Tablets given orally twice weekly.

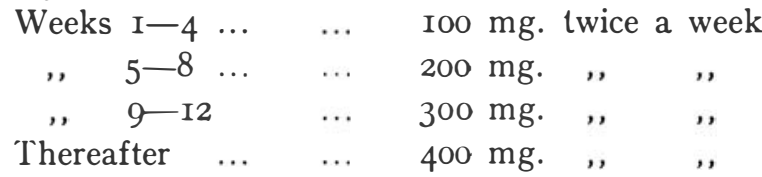

For children the dose is reduced, but not necessarily according to body weight.

The above is a standard dosage regime and should be followed where possible. A good clinical response can be obtained with smaller doses and with less frequent administration; weekly treatment is practicable and appears effective. Some workers suggest parenteral sulphone (DDS) in cocoanut oil suspension once in I4 days, and report a clinical response. These facts make outpatient treatment widely practicable.

\section{Choice of Treatment.}

The opinion of this group divided. Some advocate injections of sulphetrone because they considered it less toxic, and because they consider administration of the proper dose is easier to control, and abuse of the treatment easier to prevent.

Others think that DDS is no more toxic, is cheaper and much easier to administer. In the administration of the oral dose twice weekly, the patient should not be given tablets to take away with him unless the physician can trust him to use them according to his instructions, thus preventing serious abuse of the drug. In any case, the importation and distribution of any sulphone drug should be carefully controlled, and its administration supervised by trained medical personnel.

\section{Duration of Treatmen'r.}

Progress under treatment, though usually sure, is often very slow, and clinical improvement is usually much quicker than bacteriological improvement. Tuberculoid cases with widespread disease should be treated for at least a year to 18 months. The treatment of bacteriologically positive cases must be continued until the patient becomes and remains bacteriologically negative, and loses all clinical signs of activity. Until now the continuation of negative results for one year has commonly been the criterion for discharge. In one country a considerable relapse rate has been recorded on this regime, and it has been recommended that patients should continue treatment for a much longer period. The length of treatment should vary with the severity of the case and the time 
required to become negative. Where it is practicable the advisability of necessary periodic after-treatment with sulphones might be seriously considered.

6. SUNDRY POINTS.

(1) Sulphones in prophylaxis.

It has been suggested that sulphones should be used in persons seriously exposed to infection, as a prophylactic. Such sulphone administration would be unlikely to have any harmful effect. No evidence is yet available of the value of such prophylactic treatment. This is a matter needing careful investigation.

(2) Sulphone resistance.

So far no clear indication of any kind has been seen to show that prolonged or intermittent sulphone treatment produces sulphone resistant bacilli in the person treated.

(3) The influence of sulphone treatment on anti-leprosy work in general.

Sulphone treatment itself is not the answer to the wide problems of leprosy. Early diagnosis, the early institution of treatment, segregation of infective cases, other remedial measures (including surgery) and rehabilitation of patients, all these activities are vital. Many of these activities have, however, already been facilitated and encouraged by improved results of treatment, and the opportunity now afforded for these increased activities should be seized and used fully.

\section{Other Drugs in Treatment.}

Streptomycin, though having some action in leprosy, appears unlikely to play any major part in treatment.

The thiosemicarbazones are giving promising results, but there is no indication that they are in any way superior to sulphones. They are more expensive and less widely applicable. They appear unlikely to rival or replace sulphone treatment, but they provide a useful alternative treatment in patients in whom sulphone administration presents difficulties (particularly allergy) or produce inadequate response.

B.C.G. has been found useful, particularly by workers in Brazil, in turning negative lepromin tests into positive. In the experiment referred to, 30 children of leprous parents were given .I gm. of B.C.G. orally once a week for three weeks, the lepromin test being done on the same day as the first dose of B.C.G. was given, and all but four gradually developed positive results. After a year all the 30 children showed positive lepromin tests. At the 
same time, as a control, I5 children were lepromin tested, but were not given B.C.G., and all gave negative results. If these findings are confirmed, and if B.C.G. is found to increase the resistance of children to leprosy, we may have another important tool in combatting the disease. 